\title{
SISTEM TELEMETRI SIMULASI MITIGASI BENCANA KEGEMPAAN DAN DETEKSI PENINGKATAN KADAR KONDUKTIVITAS BELERANG PADA GUNUNG BERAPI BERBASIS WIRELESS 802.15.4
}

\author{
Yuhananisa $\mathbf{P}^{1}$, Yayan $\mathbf{P N}^{1}$, Lailatul $\mathrm{K}^{1}$, Rahil $\mathrm{L}^{1}$, Wahyu $\mathrm{SP}^{1}$, Ria $\mathbf{O}^{1}$ \\ ${ }^{1)}$ Program Studi Fisika, FMIPA, Universitas Negeri Surabaya \\ e-mail : yans.okx@gmail.com
}

\begin{abstract}
Laboratory studies on disaster simulation systems telemetry was conducted focusing on some part of the parameters to determine the character of the natural phenomena that occur. Parameters measured were conductivity levels of sulfur in marine volcanic and earthquake intensity. The technique is to do with the design of instrumentation tool by using vibration sensor meas vibration sensors and sensor electrode conductivity copper as sulfur. Data obtained using a telemetry system transmitted by the wireless XBee are working on 802.15.4 protocol. The data have been sent in the form of analog data is converted to digital analogue converter $(A D C)$. The parameters controlle in this simulation is the liquid volume of $10 \mathrm{ml}$, and the temperature room was $32^{\circ} \mathrm{C}$ and humidity of $73 \%$. The results of data sent to the recipient noted that the major instrument for the conductivity amounted to $0.01361 \mathrm{~K}^{-1} 1 \mathrm{in}$ 0 gmass. The data $5.011 \mathrm{~g}$ to $20.002 \mathrm{~g}$ are having conductivity between $0.01000 \mathrm{~K} \Omega^{-1} 1$ to 0.01418 $K \Omega^{-1}$. The data result of Vibration sensor at $0 \mathrm{~g}$ to $20002 \mathrm{~g}$, have voltagesammounted2.752 volts, worth voltage increases to 3.724 volts.
\end{abstract}

Keywords: Xbee, Conductivity, Vibration sensor, Simulation, Wireless Simulation

\begin{abstract}
Abstrak
Penelitian laboratorium tentang sistem simulasi telemetri kebencanaan ini dilaksanakan fokus pada beberapa bagian dari parameter kebencanaan untuk mengetahui karakter dari gejala alam yang terjadi. Parameter yang diamati adalah konduktifitas kadar belerang pada perairan gunung berapi dan intensitas gempa yang terjadi. Tehnik yang dilakukan adalah dengan perancangan alat instrumentasi dengan menggunkan sensor getar meas vibration sensor dan elektroda tembaga sebagai sensor konduktivitas belerang. Data yang diperoleh dikirimkan dengan sistem telemetri menggunakan Xbee wireless dengan protokol 802.15.4. Data yang telah dikirimkan berupa data analog yang diubah dalam bentuk analogue to digital converter (ADC). Parameter yang dikontrol dalam simulasi ini adalah volume cairan sebesar $10 \mathrm{ml}$, serta suhu ruang sebesar $32{ }^{\circ} \mathrm{C}$ dan kelembapan sebesar 73\%. Hasil-hasil data yang terkirim pada instrumen penerima tercatat bahwa besar konduktivitas untuk masa $0 \mathrm{gr}$ sebesar $0.01361 \mathrm{~K} \Omega^{-1}$. Untuk data mulai $5.011 \mathrm{gr}$ hingga 20.002 gr besarnya konduktivitas adalah antara $0.01000 \mathrm{~K} \Omega^{-1}$ hingga $0.01418 \mathrm{~K} \Omega^{-1}$. Data sensor getaran antara percobaan $0 \mathrm{gr}$ hingga $20.002 \mathrm{gr}$ besarnya dalam satuan tegangan bernilai 2.752 volt meningkat sampai 3.724 volt.
\end{abstract}

Kata Kunci: Xbee, Konduktivitas, Sensor getar, Simulasi, Simulasi Wireless 


\section{PENDAHULUAN}

Indonesia merupakan negara kepulauan yang dikelilingi oleh sirkum Pasifik dan sirkum Mediterania. Keadaan ini yang menyebabkan Indonesia menjadi negara yang memiliki banyak gunung berapi yang masih aktif, salah satu contohnya adalah gunung Merapi yang masih aktif dan memiliki letusan yang sangat berbahaya (Troll, 2012: 38). Banyaknya gunung di Indonesia yang masih aktif menyebabkan seolah negara Indonesia dalam suatu ancaman bahaya gunung meletus maupun bahaya tsunami. Dengan ancaman tersebut, maka diperlukan suatu sistem monitoring terhadap aktivitas gunung berapi maupun deteksi tsunami guna memberikan informasi terhadap keadaan tersebut. Informasi yang diperlukan tentunya adalah informasi yang bersifat real time. Informasi yang bersifat real time akan memberikan kekinian tentang status maupun aktivitas gunung yang sedang di-monitoring. Perpaduan kemajuan teknologi telekomunikasi dan sistem pengolahan data akusisi yang akurat dapat dimanfatkan untuk menjawab kebutuhan lapangan tentang berbagai permasalahan, baik untuk monitoring maupun untuk proses telekomunikasi dan sistem telemetri.Seiring dengan perkembangan ilmu dan teknologi saat ini, maka untuk memenuhi kebutuhan tersebut kita dapat memanfatkan beberapa piranti teknologi instrumentasi maupun teknologi telekomuniksi yang moderen.Teknologi ini terdiri dari teknologi detektor aktivitas gunung berapi maupun teknologi untuk memindahkan informasi yang lebih akurat dan efisien. Untuk merealisasikan hal tersebut maka tentunya berbagai institusi baik dari akademis maupun institusi peneliti serta yang lainnya gencar melakukan riset-riset dengan tujuan untuk sistem monitoringguna untuk mitigasi bencana. Salaha satu peran yang diambil dari topik hangat tersebut adalah melakukan penelitian perancangan intrumentasi kebencanaan dalam sekala laboratorium untuk mensimulasikan gunung yang meletus.Ada beberapa parameter yang dapat dijadikan acuan untuk memantau aktivitas gunung berapi, beberapa dantaranya adalah gempa bumi, konduktivitas perairan pada ouncak gunung berapi, kondisi gas seperti $\mathrm{S}$, $\mathrm{H}_{2} \mathrm{O}, \mathrm{CO}_{2}$ dan temperatur seperti pada letusan gunung merapi contohnya (Nadeau, 2012: 50). Dalam penelitian ini akan mengambil parameter konduktifitas air pegunungan yang mengandung belerang dan getaran yang diperoleh dari data tremor sebagai bahan simulasi.

Bahan Konduktor yang baik adalah bahan yang mudah mengalirkan arus listrik, umumnya terdiri dari logam dan air. Kemampuan suatu bahan untuk menghantarkan arus listrik ditunjukkan oleh besarnya harga konduktivitas listrik atau daya hantar listrik bahan tersebut. Kebalikn dari harga konduktivitas listrik suatu bahan adalah resistivitas atau hambatan jenis (Halliday, 2011: 690) yang memiliki hubungan:

$$
\rho=\frac{1}{\sigma}
$$

dimana $\rho$ merupakan kerapatan atau hambatan jenis dari suatu bahan $(\Omega m)$,sedangakan untuk $\sigma$ merupakan konduktivitas dari suatu bahan (Mho/m). seperti yang kita ketahui behwa kemampuan bahan untuk menahan arus listrik yang mengalir melalui penampang bahan ditunjukkan oleh harga hambatan listriknya dengan persamaan sebagai berikut:

$$
R=\frac{\rho L}{A}
$$

Dengan $R$ merupakan hambatan listrik (Ohm), untuk $L$ merupakan panjang penghantar (m), sedangkan untuk $A$ merupakan luas penampang dari penghantiar listrik dengan satuan $\left(\mathrm{m}^{2}\right)$.

Untuk kasus penghantar yang dilalui arus listrik maka berlaku persaman hukum Ohm yang dinyatakan dengan :

$$
V=I \cdot R(3)
$$

dimana $V$ merupakan beda potensial dari arus listrik (Volt), sedangkan I merupakan arus listrik yang mengalir dalam suatu 
penghantar (Ampere).Data hasil percobaan merupakan data dalam bentuk analog yang nilainya dikonvesikan dalam suatu persamaan yang diolah dalam sebuah mikrokontroler edngan persamaan:

$$
V=[(A D C+1) * 5] / 1024
$$

dimana dengan persamaan dengan $A D C$ merupakan nilai digital hasil bacaan mikrokontroler sedangkan $V$ merupakan tegangan terukur pada sensor (Votl). Hasil konduktivitas diperoleh dari perhitungan dengan persamaan sebagai berikut:

$$
G=I / V
$$

dengan $G$ merupakan konduktivitas bahan yang dialiri arus dan memiliki beda potensial $\left(\Omega^{-1}\right)$ sedangkan untuk I merupakan besaran arus listrik (mA) dan $\mathrm{V}$ tegangan terukur pada sensor (Votl). Untuk mengukur besar konduktivitas bahan dengan memanfaatkan hubungan persamaan antara persamaan (3) dan persamaan (5) maka didapatkan hubungan:

$$
G=1 / R
$$

Perkembangan dunia digital dan telekomunikasi (Rao, 2005: 6), dan lahirnya banyak varian telekomunikasi(Ergen, 2005: 1), tentunya turut membantu dalam proses sistem telemetri dan pengiriman data akusisi. Pemanfaatan teknologi tersebut dapat diimplementasikan dalam beberapa fungsi yaitu untuk monitoring system(Rao, 2005: 6) pada perumahan, industri, bangunan, pertokoan, telekomunikasi, hingga untuk proses telemetri kebencanaan. Menurut (Nugraha, 2013:1) perkembangan sistem telemetri ini dengan perkembangan teknologi yang lebih canggih dapat dimanfaatkan untuk multi nodes networking pada pengiriman data akusisi. Selain itu dengan memanfaatkan hardware Xbee Pro 24 ACI 001 telah terbukti mampu mengirimkan data dengan jangkauan $1.5 \mathrm{Km}$ (Nugraha, 2013:1).

\section{METODE PENELITIAN}

Penelitian simulasi laboratorium ini merupakan basis dari Field Based Research yang dapat diimplementasikan pada beberapa pegunungan aktif yang ada di Indonesia. Langkah penelitian dimulai dari perancangan sensor yang terdiri dari sensor getar (meas vibration sensor) yang menggunkan sistem pembagi tegangan dan datanya dimasukkan dalam mikrokontroler yang dibuat. Instrumentasi yang dipakai terintegrasi dalam suatu paket instrument system box(Gambar 1) yang berfungsi mengolah data hasil masukan dari sensor.

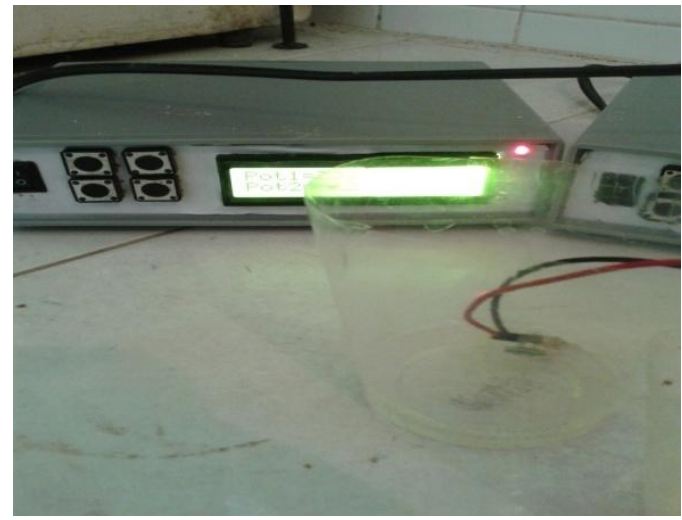

Gambar 1. Instrument system box

Sebelum melaksanakan perancangan alat tersebut, maka dilakukan perancangan ke dalam bread board untuk diteliti apakah sistem yang digunakan benar-benar valid ataupun tidak. Pengujian meliputi pengujian minimum system yang menggunkan Atmega8 sebagai prosesornya. Untuk proses transmisi data digunakan sistem telemetri yaitu dengan menggunakan Xbee. Pengujian tahap awal adalah pengujian analogue to digital converter(ADC) yang terkirim secara telemetri menggunakan wireless Xbee. Berikut metode pengujiannya pada Gambar 2:

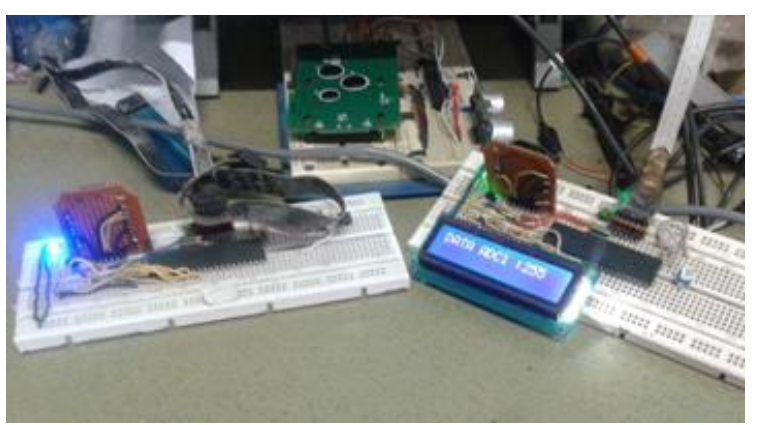

Gambar 2. Pengujian dengan menggunkanbread board 
Padatahapan selanjutnya adalah pengambilan data dengan memberikan variasi masa sulfur dalam setiap proses pengambilan data. Dengan cairan pelarut yang dijaga untuk volumenya yang digunakan dalam percobaan ini adalah sebesar $10 \mathrm{ml}$. Sedangkan untuk variasa masa adalah sebesar 5 gr, 10 gr, 15 gr, dan 20 gr. Setiap pengambilan data didasarkan atas jumlah variasi masa. Data yang diambil adalah besar konduktivitas bahan yang diuji dan nilai dari sensor getaran tersebut. Setelah itu data diukur dalam dua proses yaitu pengukuran tak langsung yang dapat diambil datanya dari mikrokontroler dan pengukuran langsung menggunkana multimeter. Kedua proses pengambilan data ini dibandingkan hasilnya. Secara umum Gambar 3 merupakan gambaran secara umum tentang proses pengambilan data.

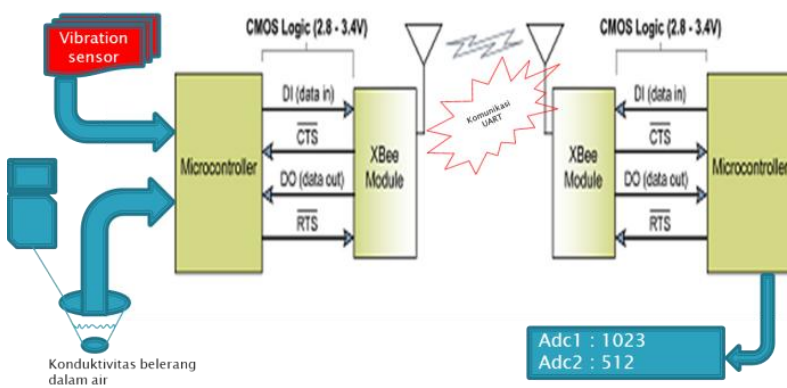

Gambar 3. Teknik pengambilan data

\section{HASIL DAN PEMBAHASAN}

Hasil penelitian yang berbasis penelitian laboratorium ini memberikan gembaran informasi yang dapat diajadikan basis penelitian selanjutnya yang relevean. Hasil penelitian ini mengacu pada hasil-hasil yang diperoleh dari eksperimen laboratorium dengan membandingkan antara pengukuran oleh mikrokontroler dan pengukuran oleh multimeter. Pengukuran yang dilakukan adalah mengukur secara langsung hambatan dan getaran yang diperoleh dari hasil pembacaan sensor konduktivitas dan vibration sensor. Kedua sensor tersebut bekerja dalam satu unit mikrokontroler yang datanya dikirimkan melalui wireless. Bacaan sensor yang dikirimkan merupakan bacaan secara analog. Hasil pengiriman data secara analog inilah yang akan dimanfaatkan datanya untuk mengetahui kadar konduktivitas dalam zat cair. Beberapa parameter percobaan yang didapatkan yaitu suhu ruang laboratorium tempat pengukuran adalah $32{ }^{\circ} \mathrm{C}$, untuk kelembapan pada tempat percobaan sebesar $73 \%$. Tegangan suplai untuk sensor konduktivitas memanfaatkan tegangan 5 Volt yang diperoleh dari power suppaly mikrokontroler. Hasil-hasil eksperimen tersaji dalam tabel di bawah ini:

Tabel 1.Hasil-hasil eksperimen pengukuran konduktivitas dengan mikrokontroler

\begin{tabular}{|c|c|c|c|c|c|c|c|}
\hline \multirow{2}{*}{ No. } & \multirow{2}{*}{$\begin{array}{c}\text { massa } \\
(\mathrm{gr})\end{array}$} & \multicolumn{2}{|c|}{$\begin{array}{c}\text { Sensor } \\
\text { Konduktivitas }\end{array}$} & \multicolumn{2}{|c|}{$\begin{array}{l}\text { Sensor } \\
\text { Getaran }\end{array}$} & \multirow{2}{*}{$\begin{array}{c}\text { Arus } \\
\text { Listrik } \\
(\mathrm{mA})\end{array}$} & \multirow{2}{*}{$\begin{array}{c}\text { Konduk. } \\
\left(\mathrm{K} \Omega^{-1}\right)\end{array}$} \\
\hline & & $\begin{array}{l}\text { Nilai } \\
\text { ADC }\end{array}$ & $\begin{array}{l}\text { Teg. } \\
(\mathrm{V}) \\
\end{array}$ & $\begin{array}{l}\text { Nilai } \\
\text { ADC }\end{array}$ & $\begin{array}{l}\text { Teg. } \\
\text { (V) }\end{array}$ & & \\
\hline 1 & 0 & 505 & 2.468 & 563 & 2.752 & 0.034 & 0.01361 \\
\hline 2 & 5.011 & 477 & 2.331 & 597 & 2.918 & 0.023 & 0.01000 \\
\hline 3 & 10.009 & 547 & 2.674 & 610 & 2.981 & 0.03 & 0.01116 \\
\hline 4 & 15.009 & 550 & 2.688 & 685 & 3.348 & 0.033 & 0.01224 \\
\hline 5 & 20.002 & 609 & 2.977 & 762 & 3.724 & 0.042 & 0.01418 \\
\hline
\end{tabular}

Dari informasi yang telah diperoleh dari Tabel 1 di atas, tegangan yang didapatkan diperoleh dari hasi konversi Analogue to Digital Converter (ADC) memenuhi suatu perumusan untuk mendapatkan nilai tegangan seperti dalam persamaan yang telah tersebut di atas. Informasi yang diperoleh berdasarkan Tabel 1 tersebut memberikan hasil pengukuran konduktivitas secara tidak langsung dari masing-masing eksperimen yaitu dengan masa belerang 0 gr sebesar 2.468 Volt dengan arus $0.034 \mathrm{~mA}$ dengan besar konduktivitas $0.01361 \quad \mathrm{~K} \Omega^{-1}$. Perolehan pengukuran selanjutnya dengan masa 5.011 gr diperoleh konduktivitas lebih kecil yaitu sebesar $0.01 \mathrm{~K} \Omega^{-1}$. Hasil ini terus meningkat seiring dengan bertambahnya masa belerang hingga 20.002 gr didaptkan hasil konduktivitas larutan sebesar 0.01418 $\mathrm{K} \Omega^{-1} 1$. Selain hasil tersebut, perlakuan terhadap sensor getaran untuk diberikan usikan yang meningkat seiring dengan bertambahnya masa belerang dapat diamati pada tabel di atas, bahwa ketika usikan yang diberikan semakin besar, maka nilai tegangan yang dihasilkan juga semakin besar. Besarnya getaran dapat teramati dalam analisis yang menggambarkan nilai tegangan 
yang terus naik mulai dari $2.752 \mathrm{~V}$ pada saat masa 0 gr dan meningkat hingga $3.724 \mathrm{~V}$ pada saat masa 20.002 gr. Sebagai bahan perbandingan pengukuran, maka pengukuran selanjutnya menggunakan multimeter untuk mengetahui hambatan bahan pada larutan belerang tersebut. Hasil-hasil pengukuran dengan menggunakan multimeter akan didapatkan pada tabel berikut:

Tabel 2. Hasil-hasil eksperimen pengukuran konduktivitas dengan multimeter

\begin{tabular}{|c|c|c|c|c|c|}
\hline \multirow[b]{2}{*}{$\begin{array}{l}\mathrm{N} \\
\mathrm{o}\end{array}$} & \multirow[b]{2}{*}{$\begin{array}{l}\text { mas } \\
\text { sa } \\
(\mathrm{gr})\end{array}$} & \multirow[b]{2}{*}{$\begin{array}{c}\mathrm{R}(\mathrm{K} \\
\Omega)\end{array}$} & \multicolumn{2}{|c|}{$\begin{array}{c}\text { Sensor } \\
\text { Getaran }\end{array}$} & \multirow[b]{2}{*}{$\begin{array}{c}\text { Kondukti } \\
\text { vitas } \\
\left(\mathrm{K} \Omega^{-1}\right)\end{array}$} \\
\hline & & & $\begin{array}{l}\text { Nil } \\
\text { ai } \\
\text { AD } \\
\text { C }\end{array}$ & $\begin{array}{c}\text { Tegan } \\
\text { gan } \\
(\mathrm{V})\end{array}$ & \\
\hline 1 & 0 & 73.5 & $\begin{array}{c}56 \\
3\end{array}$ & 2.752 & 0.01361 \\
\hline 2 & $\begin{array}{c}5.01 \\
1\end{array}$ & 100 & $\begin{array}{c}59 \\
7\end{array}$ & 2.918 & 0.01000 \\
\hline 3 & $\begin{array}{c}10.0 \\
09 \\
\end{array}$ & 89.6 & $\begin{array}{c}61 \\
0 \\
\end{array}$ & 2.981 & 0.01116 \\
\hline 4 & $\begin{array}{c}15.0 \\
09 \\
\end{array}$ & 81.7 & $\begin{array}{c}68 \\
5 \\
\end{array}$ & 3.348 & 0.01224 \\
\hline 5 & $\begin{array}{c}20.0 \\
02\end{array}$ & 70.5 & $\begin{array}{c}76 \\
2 \\
\end{array}$ & 3.724 & 0.01418 \\
\hline
\end{tabular}

Dari pengamatan Tabel 2 di atas, didapatkan hasil pengukuran konduktivitas. Hasil pengukuran pada masa 0 gr pada larutan belerang diperoleh konduktivitas sebesar $0.01361 \mathrm{~K} \Omega^{-1}$. Hasil ini sesuai dengan hasil yang diperoleh dari pengukuran melalui data ADC pada Tabel 1 yang memiliki hasil yang sama.

Data pengukuran dengan masa 5.011 gr yang diperoleh dari tabel 2, didapatkan nilai konduktivitas sebesar $0.01 \mathrm{~K} \Omega^{-1}$. Hasil yang sama juga diperoleh pada pengukuran menggunakan mikrokontroler yaitu sebesar $0.01 \mathrm{~K} \Omega^{-1}$. Hasil ini terus meninggkat hingga pada masa 20.002 gr memiliki nilai konduktivits sebesar $0.01418 \mathrm{~K} \Omega^{-} 1$. Hasil ini murupakan data yang memiliki hasil yang sama sesuai pada tabel 1. Selain itu pengukuran yang selanjutnya adalah dari sensor getaran yang juga masih memiliki hasil yang sama yaitu sebesar 2.752 Volt untuk masa belerang 0 gr dan 3.724 Volt untuk masa belerang 20.002 gr. Hasil ini menunjukkan kesamaan terhadap data yang diperoleh dari Tabel 1 di atas.

Data-data yang diperoleh dari kedua tabel di atas secara umum dapat tergambarkan dalam suatu grafik yang mana menyatakan besaran konduktivitas baik yang terukur menggunakan multimeter maupun pengukuran yang terukur dengan kikrokontroler memiliki hasil yang cukup signifikan sama. Keberadaan ini memberikan informasi bahwa antara pengukuran yang diperoleh pada saat masa belrerang 0 gr hingga kadar belerang 20.002 gr memiliki hasil yang sama antara pengukuran dengan multimeter maupun mikrokontroler sebesar $0.01361 \mathrm{~K} \Omega^{-1}$ hingga $0.01418 \mathrm{~K} \Omega^{-1}$. Data ini tentunya dalam aplikasi lapangan memberikan suatu informasi bahwa ketika kondisi cairan kaldera ataupun mata air yang berada pada puncak gunung belum tercampur belerang, maka nilai konduktivitasnya mendekati $0.01361 \mathrm{~K} \Omega^{-1}$. Seiring dengan bertambahnya campuran belerang dalam cairan tersebut, data dapat diamati sesuai pada grafik Gambar 1. Data untuk kondisi campuran yang masih encer sekali yaitu 5.011 gr maka konduktivitas cenderung rendah, hal ini dimungkinkan karena konduktivitas dari air tersebut berkurang akibiat adanya campuran substansi baru dari belerang, keadaan ini menjadikan ruang gerak untuk mobilitas arus listrik menjadi sulit kare sifat campurannya tidak bersifat elektrolit. Seiring dengan bertambanya kandungan belerang, tingkat konduktivitas juga akan meningkat sampai pada saat nilai masa belerang tersebut memenuhi harga 20.002 gr dengan konduktivitas $0.01418 \mathrm{~K} \Omega^{-1}$. 


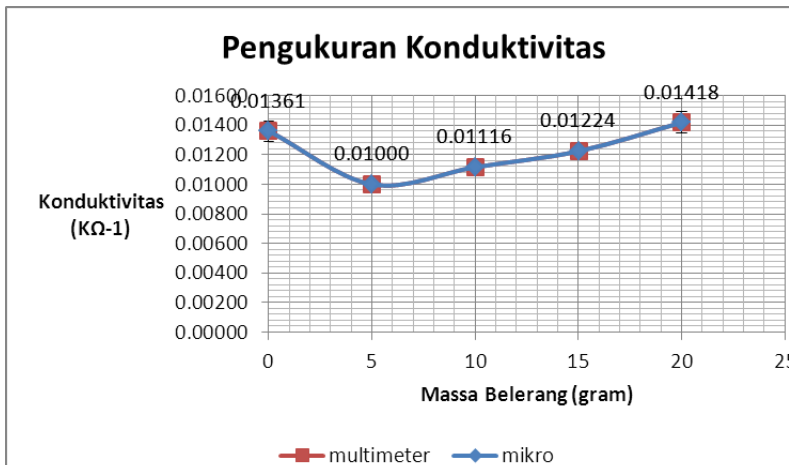

Gambar 4. Grafik Pengukuran konduktivitas dengan mikrokontroler dan multimeter

Data yang diperoleh dari kedua tabel di atas memberikan gambaran bahwa data nilai sensor getar pada saat pengkuran konduktivitas dengan mikrokontroler dan dengan menggunakan multimeter, sensor getaran di-triger atau diusik sedemikian hingga usikan yang semakin meningkat seiring dengan bertambhanya massa. Hal ini dilakukan untuk memberikan simulasi terhadap getaran yang ada pada aplikasi lapangan. Bahwa untuk getaran pada saat kondisi 0 gr belerang pada air $10 \mathrm{ml}$, maka konduktivitasnya hannya diperoleh dari air saja. Simulasi ini memberikan gambaran bahwa dengan getaran yang kecil biasanya belum terdapat campuran belerang, karena energi endogen magma suatu gunung berapi masih belum terambatkan sampai menuju permukaan tanah, apabila getaran semakin besar, maka efek dari kandungan magma yang salah satunya adalah cairan sulfur akan juga perlahan keluar dari bagian ujung gunung tersebut. Simulasi ini juga menggambarkan seiring dengan bertambahnya belerang, juga bertambah pula getarannya. Untuk kasus yang memiliki getaran sangat besar sekali, maka nilai kepekatan dari cairan tersebut menjadi lebih tinggi karena kandungan belerang juga semakin tinggi pula. Hasil pengukuran baik yang diperoleh pada saat pengukuran konduktivitas dengan menggunakan multimeter dan menggunakan mikrokontroler dilakukan pada saat yang bersamaan dan pengukurannya nilai getaran yang diperoleh keduanya juga sama. Berikut merupakan grafik hasil sensor getaran dengan menggunakan vibration sensor tipe "MeasSensor".

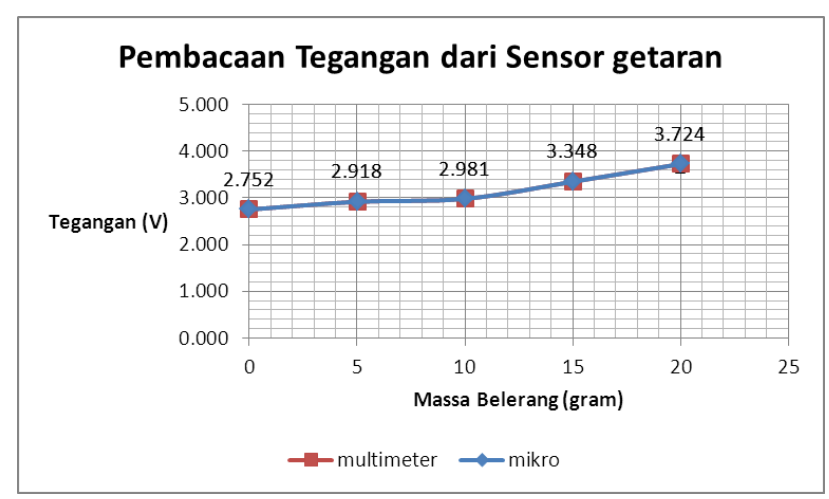

Gambar 5. Grafik pembacaan tegangan dari sensor getaran masa yang ditambahkan.

\section{SIMPULAN DAN SARAN}

Data-data yang diperoleh dari percobaan eksperimen ini diperoleh beberapa hasil sensor konduktivitas baik yang terukur menggunakan multimeter maupun data-data yang terukur menggunakan mikrokontroler. Kedua data ini memiliki hasil yang cukup signifikan dan sama yaitu dengan mengkontrol volume cairan sebesar $10 \mathrm{ml}$, dengan suhu ruang laboratorium sebesar 32 ${ }^{\circ} \mathrm{C}$ dan humidity sebesar $73 \%$, maka nilai konduktivitas didapatkan sebesar 0.01361 $\mathrm{K} \Omega^{-1} 1$ untuk masa 0 gr dan $0.01418 \mathrm{~K}^{-1} 1$ untuk masa belerang 20.002 gr. Hasil ini tidak linier namun ketika terdapat campuran belerang 5.011 gr konduktivitas mulai turun dengan harga $0.01000 \mathrm{~K} \Omega^{-} 1$ dan konduktivitas akan naik lagi seiring dengan bertambahnya kandungan sulfur dalam cairan tersebut. Nilai getaran yang diperoleh diatur supaya usikan yang diberikan juga memiliki tingkatan sesuai jumkah dari masa belerang yang diberikan. Dari data getaran tersebut didapatkan hasil pembacaan sensor getaran yang telah terkonversi menjadi data analog tegangan yaitu sebesar 2.752 Volt hingga 3.724 Volt. Hasil-hasil pengukuran menggunakan multimeter maupun mikrokontroler menunjukkan hasil yang cukup signifikan dan sama.

Saran yang dapat diambl dari penelitian awal ini adalah ditambahkannya tingkat rentang manipulasi masa agar data yang diperoleh juga mengalami ketelitian yang 
cukup baik. Selain itu agar kontrol sensor getar pada penelitian selanjutnya sudah dapat terkalibrasi dengan baik menggunakan satuan Sekala Richter.

\section{UCAPAN TERIMAKASIH}

Ucapan terimakasih yang sedalamdalamnya untuk Dosen Tjipto Prastowo, Ph.D yang banyak memberikan ilmu dan pengalaman hidup untuk menjadi mahasiswa yang lebih baik.

\section{DAFTAR PUSTAKA}

Ergen, S. C. (2005). ZigBee/IEEE 802.15.4 Summary. In Ergen. Berkeley, California. Nadeau, O. (2013). Magmatic Hydrothermal Evolution And Devolatilization Beneath Merapi Volcano, Indonesia. Montreal, Canada: Journal of Volcanology and Geothermal Research, p50-p68 Elsevier journal.
Nugraha, Y.P. (2013). Transmisi Data Melalui Gelombang Elektromagnetik Dengan Menggunakan Modul Xbee Pro 24-Aci-001. Surabaya: Jurnal Fisika. Volume 02 Nomor 03 Tahun 2013, 1 - 4.

Nugraha, Y.P. (2013). Transmisi Data Melalui Sistem Komunikasi Frekuensi Radio Dengan Menggunakan Modul Xbee Pro 24-Aci-001. Tangerang: Seminar Nasional Fisika 2013 LIPI, ISSN 2088-4176

Rao, V. P. (2005). The simulative Investigation of Zigbee/ IEEE 802.15.4. Dresden: Dresden Univesity Of Technology.

Halliday. D. (2011). Fundamental of Physics $9^{\text {th }}$. United States of America: John Wiley \& Sons, Inc. All rights reserved

Troll, V.R. (2012). Magmatic Differentiation Processes At Merapi Volcano: Inclusion Petrology AndOxygen Isotopes. 